concerns the faculty of laughter. The poem he wrote as an epigraph to the second book he published (Gargantua) contains the following lines:

It is better to write about laughter than tears,

For laughter is the property of man.

Rabelais is here referring to the accepted wisdom of his day: God does not laugh (except, in the Old Testament, to laugh his enemies to scorn); animals, which share much of their nature with humans, do not laugh. This uniquely human faculty was seen as a medical conundrum; neither what caused it nor its function was clear. ${ }^{7}$

Rabelais, the religious moderate, was also a strong believer in the interdependence of the mind and body and the value of human company and merriment. He argues that the laughter produced by his books will be therapeutic laughter, restoring in a holistic way not only a sense of proportion to the mind but also health to the body; and he dedicates his writings to the pox ridden and gouty, in human companionship, wishing them a life of "peace, joy and good health, never short of a good meal." The laughter provoked by the giant tales is, it is true, sometimes directed at other people, but it is mainly enjoyed with other people; it is healing, socially cohesive, unmalicious. Not bad treatment, when taken in the form of doses of reading from Rabelais's tales.

IAN MACLEAN Reader in French

Queen's College,

Oxford OX1 4AW

1 Rabelais F. The histories of Gargantua and Pantagruel. Harmondsworth: Penguin, 1955. (Translated by J M Cohen).

Plattard J. La vie et l'oeuvre de Rabelais. Paris: Hatier, 1939.

3 Screech MA. Rabelais. London: Duckworth, 1979.

3 Screech MA. Rabelais. London: Duckworth, 1979.

5 A dictionary of scientific biography. New York: American Council of Learned Societies, 1970-80: ix:74-5.

6 Maclean I. The Renaissance notion of woman. Cambridge: Cambridge University Press, 1980:28-46.

7 Screech MA, Calder RM. Some Renaissance attitudes to laughter. Humanism in France. Manchester Manchester University Press, 1970:216-28.

\title{
Recovery from anaesthesia
}

\section{Specially designated recovery areas are essential}

The Confidential Enquiries into Maternal Deaths and the National Confidential Enquiries into Perioperative Deaths regularly emphasise the clinical problems associated with recovery from anaesthesia. ${ }^{12}$ Despite their proliferation over the past few decades recovery rooms-designated places for sole occupancy by patients who have just had operations-are not always fully staffed with competent people when they are needed, and equipment may be missing. Why should this be? Why is it that one in seven patients dying perioperatively could not be admitted to a special area for their care because no recovery room apparently existed? ${ }^{2}$ Other patients who subsequently died were denied access because the unit was closed or not staffed at night.

Managers must appreciate that the physical existence of a designated recovery room does not mean that it can be used at all times. Surgeons must realise that their wards are no longer suitable places for their patients to recover from surgery, particularly at night or weekends. "Found dead in bed" is still written in medical or nursing records about patients within 12 hours of operation: in some cases this may represent very poor care.

Anaesthetists readily acknowledge the importance of recovery rooms and understand the similarity between them and, for example, accident and emergency departments, where much of what happens is repetitive and without drama. The descriptor "post anaesthesia care unit"-commonly used in the United States-makes the advantages clear: proper management of acute pain may be started, children may be reunited with their parents soon after operation, and trainee anaesthetists have the unique opportunity to learn by observation.

Discharge from a recovery unit is often rightly delegated to nursing staff, but having trainee anaesthetists witness at first hand what happens has its advantages. This educative potential of recovery rooms is largely overlooked in Britain, as is the potential for research. ${ }^{3}$

The preventive aspects of care in the recovery room are well known and include maintaining the airway (including ventilation and oxygenation), detecting bleeding or the effects of surgical oedema, and monitoring the patient's return to the physiological state that existed preoperatively. Hypothermia is one derangement of normal physiology that should not happen in operating theatres but still does; it is an important deviation from normal, particularly in elderly people, and needs correction before the patient returns to the ward. ${ }^{4}$ Detection of rare events such as covert drug interactions; reduced or increased activity of endocrine systems; the evolution of mishaps associated with anaesthesia, such as the failure to reverse muscle relaxants or narcotic drugs; and the sympathetic management of dying patients are some of the therapeutic and diagnostic possibilities.

The Association of Anaesthetists of Great Britain and Ireland has recently issued the second of its booklets on recovery rooms. ${ }^{5}$ This one summarises the accumulated clinical experience on the topic and, more importantly, lists the basic facilities that hospitals should provide. Most hospitals in the NHS and the independent sector meet these requirements.

Commissioners of health care and purchasers should check that their providers have adequately staffed and equipped recovery rooms that are providing care to the appropriate standard. Providers should be encouraged to review their practice to ensure that they are meeting the requirements set out by the Association of Anaesthetists. The burgeoning development of day stay surgery carries with it the risk of premature discharge from units sometimes run by relatively inexperienced staff. This recent contribution from the association is therefore particularly apposite.

JOHN N LUNN Reader

Department of Anaesthetics and Intensive Care Medicine,

University of Wales College of Medicine,

Cardiff CF4 4XN

1 Report of the confidential enquiry into maternal deaths 1988-1990. London: HMSO, 1994

2 Campling EA, Devlin HB, Hoile RW, Lunn JN. Report of the national confidential enquiry into perioperative deaths 1991-2. London: NCEPOD, 1993.

$\mathrm{Knill}$ RL. Clinical research in anaesthesia. Past accomplishments and a future horizon. Anaesthesic 1990;45:271-2.

4 Ip Yam PC, Carli F. Maintenance of body temperature in elderly patients who have hip replacement surgery. Anaesthesia 1990;45:563-5.

5 The Association of Anaesthetists of Great Britain and Ireland. Immediate postanaesthetic recovery. London: AAGBI, 1993. 